\title{
O mergulho de Narciso: Os segredos da poesia em Susana Vernieri
}

\author{
Nea de Castro (FURG)
}

RESUMO: Na poesia de Susana Vernieri há um "Narciso imprudente" que, muito além da autocontemplação, ousa mergulhar nas imagens fragmentárias do espelho. Nesta comunicação, tomo os reflexos ao modo das "Instantâneas", cenas móveis, fluidas, pelas quais Beatriz Sarlo procura captar nossa contemporaneidade. O corpus do trabalho é constituído por dois livros publicados por Vernieri: Memorabilia (2005) e De(s)amores (2007). Em seu universo, a poesia renasce: "Na morte do poeta se escuta o silêncio. / As teclas e as canetas/ sussurram o segredo/ para os que tiverem a coragem/ De querer ouvir".

PALAVRAS-CHAVE: Poesia brasileira - segredo - contemporaneidade.

ABSTRACT: There is a "reckless Narcissus", in the poetry of Susana Vernieri, who is deeply involved in the fragmented imagens of a mirror. In this presentation, I follow the concept of "Instant images" suggested by Beatriz Sarlo who attempts to catch our contemporaneity. This work is based on two books by Vernieri: Memorabilia (2005) and De(s)amores (2007). On her own words, the poetry emerges from: "On the poet' s death, the silence is heard. / The keys and the pens/ whisper secretly /t o those who are courageous enough to listen to it".

KEYWORDS: Brazilian poetry - secret - contemporaneity.

A poeta gaúcha Susana Vernieri (nascida em Porto Alegre, em 1965) revela seu paideuma - João Cabral de Melo Neto, Carlos Drummond de Andrade e Manuel Bandeira - nos dois livros do corpus desta comunicação: Memorabilia (2005) e De(s)amores (2007). Coloca assim sua poesia sob o signo do sincretismo da lira e da antilira, com liberdade para caminhar pelos desvãos, porões, e revelar ao leitor o inconfessável. Dialoga com os que celebram o desvio - Lord Byron, Gertrude Stein, Caio Fernando Abreu, Marisa Monte, entre outros - e com os materiais heteróclitos destes tempos: a cena literária, a que pertence também como doutora em literatura, condição comum a diversos poetas atuais; a imprensa, que conhece de dentro, como jornalista; e as cidades, que percorre como viajante, com suas vitrines, vias, caminhos, rios. Por tudo isso sua arte poética adquire matizes diversos, do tom acre, como de 
confissão entrecortada, a vozes mais leves e lúdicas, da atmosfera quase trash à reflexão elevada.

Em seu estudo exemplar, Sincretismo: a poesia da Geração 60 (1995), Pedro Lyra apresenta uma seqüência para a poesia do século XX no Brasil, à qual tenho recorrido em minhas pesquisas: Geração de 22, Geração de 45, Geração 60, e Geração de 80. A essas etapas, articuladas com base nas variantes de nascimento, estréia, vigência (que inclui, entre outros aspectos, o início do reconhecimento), confirmação e retirada, ele já agregava de modo antecipado o primeiro grupo de poetas no século XXI: a Geração-2000. Considero que Susana Vernieri pode ser identificada como parte da Geração de 80, embora sua estréia como poeta esteja deslocada para a etapa de vigência dessa geração.

Ela nasceu um ano depois da imposição da ditadura militar ao país. Como os demais autores da Geração de 80, foi se formando em meio aos efeitos do autoritarismo sobre o mundo cultural. Este se desenvolveu, sobretudo, por meio das tensões e diálogos entre as artes engajadas, que vinham desde os anos 60, e a expressão brasileira da contracultura mundial, o Tropicalismo, com origem na década seguinte. Ainda nos anos 70, como alternativa diferenciada dessas duas vertentes, surgiu a Poesia Marginal ou Poesia do Mimeógrafo. Na mesma década se disseminou o debate sobre o fim da era moderna que havia sido iniciado nos meados do século. À redemocratização do país correspondeu uma intensificação dos vínculos ao processo de globalização, com efeitos sobre a vida cultural. Em meio à ampliação e consolidação da Era Digital, os poetas que estudo se dispuseram então a recolher deslocamentos, fraturas e convocações da própria história da poesia como gênero, e da história local e dos demais países.

Penso que a obra de Vernieri, assim como todo meu corpus, pode ser classificada como poesia da hesitação. Essa expressão eu propus na tese de doutorado "O cânone da poesia brasileira em processo" (1998), orientada pela profa. Dra. Maria da 
Glória Bordini (PUCRS). Classifiquei então a obra de cinco dos dez poetas pesquisados por mim, como poesia da hesitação: Arnaldo Antunes, Augusto Massi, Alexei Bueno, Age de Carvalho, e Paulo Henriques Britto (Os outros cinco designei como autores da poética "do intermezzo", na expressão de Antônio Carlos Secchin (1996), entendida por mim como a passagem entre o modernismo e a poesia pós-moderna: José Paulo Paes, Lara de Lemos, Armindo Trevisan, Affonso Romano de Sant'Anna e Orides Fontela). Nos poetas hesitantes vi, sobretudo, uma pedagogia do paradoxo, pois a poesia perdera o discurso rigoroso que distinguia claramente a finitude, de que o modelo maior no século XX foi a arte engajada; e, num outro pólo, o discurso que permitia o sujeito lírico moderno desejar a "presença" do transcendente, de que o Drummond do "quarteto metafísico" - formado por Novos poemas (1946-1947), Claro enigma (1951), Fazendeiro do ar (1952-1953) e Vida passada a limpo (1954-1958) (MERQUIOR, 1976) - é o grande exemplo.

Ainda sob essa proposta de poesia da hesitação, a partir de 2002 iniciei junto ao Mestrado em História da Literatura (FURG) o meu Projeto "A lírica pós-moderna no Brasil", pelo qual venho estudando nossa produção contemporânea. À continuidade da leitura dos cinco autores vistos na tese, agreguei a de cinco outros autores - Rodrigo Garcia Lopes, Alckmar Luiz dos Santos, Adriano Espínola, Cláudia Roquette-Pinto, e Valdo Motta - e estou acrescentando agora Susana Vernieri. Nela já percebo, mais delineados, um tom emotivo e uma reflexão transcendente a partir do cotidiano globalizado, que se acoplam ao empreendimento metapoético próprio da Geração de 80, ou seja, à escavação dela e de seus pares em interstícios, lacunas, fragmentos da linguagem.

Confissão e metaliteratura, autor e leitor, verso e reverso, imagem e reflexo, vida e morte, amor e ódio se entrecruzam no universo de Vernieri. A poesia nasce ali onde a morte parecia haver ceifado tudo, como sinaliza "Mergulho" (p. 34-35, em Memorabilia). A comovida e densa elegia em homenagem a Caio Fernando de Abreu (falecido em 1996) se desdobra em cinco estrofes. Nas duas estrofes iniciais o leitor é 
envolvido pelo sentimento da morte do poeta através das relações paradoxais onda/metade, dia/noite e deserto/verde. "Sopro" na primeira estrofe e "fronteira" na segunda talvez prenunciem que algo conflue e se gesta:

Na morte do poeta,

a onda quebra pela metade

e o encontro do dia com a noite

fica suspenso num sopro parado.

Na morte do poeta

se faz um minuto de deserto

no vasto verde da fronteira

É possível que no leitor se avolume o sentimento da impermanência, até por impacto visual (reforçado, no livro, pelos asteriscos antes e depois da estrofe), devido ao movimento de flash-back da terceira estrofe. Mas há, simultaneamente, essa denso diálogo entre solidão e água do rio, que pode sussurrar (sim, é esse o verbo, o leitor verá no movimento final da elegia) palavras, imagens, ainda não criadas, por serem criadas, no coração do leitor:

$* * *$

Um dia,

o poeta olhava as luzes refletidas na água do rio.

Na beira do rio, mãos para trás.

Na distância necessária do meio da festa.

Na noite da cidade, só. 
Nas duas estrofes finais é que o movimento transcendente amadurece: a morte do poeta pode fazer fronteira com a vida e a arte, no concerto de teclas, canetas, vozes, tempo. Mas é preciso que haja alguém (um outro poeta, um leitor) que acolha essas vozes através de um dar-se (mergulhar) profundo:

Na morte do poeta se escuta o silêncio.

As teclas e as canetas

sussurram o segredo

para os que tiverem a coragem

de querer ouvir.

Na morte do poeta,

as vozes param,

o tempo emudece

e o homem mergulha no rio.

Foi essa elegia que me propiciou uma das possíveis leituras de Memorabilia e De(s)amores. Nos dois livros, o ato de mergulhar pode ser visto como simbolização ora do intercurso entre água, nascimento e renascimento, ora dos elos entre arte, criação e recriação. Memorabilia é aberto em tom de segredo: a dedicatória é "Para.". A epígrafe apresenta uma citação de Drummond, como um guia para os paradoxos da arte da poesia: "Não cantarei o morto:/ é o próprio canto". Como prefácio, o estudo da poeta e teórica da poesia Maria do Carmo Campos, intitulado Nas cirandas do vivido: "Com as tintas daquela justa brevidade que assinala sólida vertente da poesia contemporânea, 
Memorabilia apresenta um lirismo preciso, ágil, lúcido, comovente. Intelectuais e sensoriais, os poemas miram o destino da escrita e os múltiplos meios que a envolvem".

Memorabilia traz, na folha de rosto, o título acompanhado de um subtítulo: São objetos pessoais do acervo de um escritor. A referência metaliterária conduz o leitor a tomar como itens desse acervo as cinco partes do livro: Letras, a que se integra a elegia Mergulho; Silêncios, Passos, Corpos, e Amor. Em Letras, o primeiro poema, intitulado "Ohlepse" (p. 16-17) já propõe ao leitor uma mudança de olhar, o reverso do espelho:

.otrever, otrevnl

?otriviD

.osrever,otnevnI

?osreviD

O jogo dos signos, que inclui a conversão feita pelo leitor para a linguagem diária, aponta para sentidos diferenciados da palavra poética. No primeiro diálogo do sujeito lírico com o leitor a "reverto" e "invento" ele contrapõe a indagação "Divirto?"; no segundo, a "reverso" o e "invento", quem lê é questionado por um "Diverso?". Há então o jogo de reverter, estabelecer o reverso, inventar, mas há também dúvidas sobre o alcance e natureza desse jogo. O desafio ao leitor, outra das marcas dos dois livros de poesia de Susana Vernieri, vai assumir um tom mais provocativo em "Lógica da inutilidade" ( p. 18-19) desde o preâmbulo: "De que adianta escrever poesia / se não entendes". No dístico final, as sentenças corrosivas: N"ão entendes, não lês, não pensas / Não escrevo".

É no segundo item de Memorabilia - Vitrine - que o leitor encontra o poema "Vitrine de souvenirs ou Memorabilia" (p. 22-24). Com ele, uma espécie de trégua poeta-leitor graças ao compartilhamento do "segredo" (eco da penúltima estrofe da elegia "Mergulho?") e dessa contemplação da poesia - eis aí a metafórica "vitrine de 
souvenirs" - feita de entrevisão e memória, de presença (livros, estantes) e lapsos, vazios ( sublinhados, paradoxalmente, pela lacuna visual entre a penúltima e última estrofes):

Ganhava livros de poesia,

olhava a infinidade das letras

expostas uma a uma ao lado das outras,

Olhava a natural diversidade

e, de certo modo,

percebia as sílabas.

Enchia as estantes

com a explosão de cores

das capas e das lombadas

e enfeitava a sala forrando

as paredes

como se toda ela fosse

uma vitrine de souvenirs.

Só não sabia o que eram versos,

nem descobria o segredo oculto

nas dedicatórias.

A leitura irá desvendando os itens seguintes - Silêncios, Passos, Corpos, para concluir em Amor, de que "Tambor" (p. 96-97) é uma peça emblemática do cantar amoroso de Susana Vernieri, feito sobretudo de confissão e versos lúdicos, de entrega e distanciamento:

O ritmo te intima

Te livra, te solta 
Dança comigo

Ao som do tambor?

Baila comigo

Sob a lua do equador:

The drum is the most important

Instrument

Meu coração bate por ti

E eu toco bumbo na banda

do colégio

De(s)amores expõe a letra s entre parênteses, como indicação performática das duas partes do livro: a primeira, Deamores, que apresenta, entre outros poemas, "Mergulho" e "Mergulho II"; e a segunda, Desamores, que traz contos, entre eles "O mergulho". Neste livro a poeta optou por colocar duas epígrafes: na de Deamores, o leitor acolhe o amor antitético, na citação de Camões: "Amor é um não querer mais que bem querer"; na de Desamores, a negatividade, o conflito atormenta o amor, na citação de Lord Byron: "Pois o ódio é, de muito, o prazer mais longo; os homens amam depressa, mas detestam devagar". Ao longo do livro, então, caminho através da experiência do amor como ambigüidade, exercício de máscaras, tal como a dedicatória: " A quem inspirou". Mas há momentos de certa paz e elevação, como em "De suspiros e versos" (p. 15), o primeiro poema de Deamores. Pelo amor a persona lírica está religando arte e Deus. Está em "suspenso", por um instante, a inquietação, embora ela ronde nas aliterações nasalizadas da própria palavra "Suspenso" e em "Latente", "fino", "pungente", e "Crente":

Frágil é o suspiro de Deus

Suspenso no ato de amor 
Ele fica no ouvido presente

Latente, fino, pungente.

Ágil é o verso simples

Escrito em silêncio

Ele fica impresso sem preço

Vivo, limpo, doce.

Crente.

A poesia está escrita em silêncio, em Susana Vernieri. Por isso tudo se desdobra: o positivo está feito de negativo, este por aquele; não se trata de dualidade, mas sim de simultaneidade, como em "Beijo" (p. 17) e sua única estrofe:

Todas as tesouras

O fio

Lâmina voraz

Eu sangro no corte

Da tua boca na minha boca

Metalinguagem e amor estabelecem interconexões, trocas, na exposição do paideuma em "O meu amor" (p. 31):

O meu amor ascende na espinha

Lembra verso de Drummond

É festa com bandeirinha

Pois rodopio em fogueiras faceira

Salto do chão como em noite de São João 
O meu amor recende a incenso

Dele penso em Bandeira

No rio profundo correndo dentro de mim

Cheiros de jasmim

Alecrim

O meu amor pressente Cabral

É de cimento e cal

De pedra, areia, ampulheta,

Areal.

No canto de Vernieri o amor é então movimento criativo, construtivo, mas pode se tornar também experiência de dor a ser assimilada. Em ambos os casos, propicia matéria autorreflexiva para a poeta. Em De(s)amores, percebo no poema "Mergulho" (p. 28) um diálogo intertextual em relação a um conto de fadas dos Irmãos Grimm, "A Gata Borralheira". A mulher vive uma perda, mas à diferença da personagem canônica, ela não reassume o cotidiano após as doze badaladas, pois deseja acolher seu trauma. Transcrevo todo o poema:

Com um colar de coral e um copo de cristal celebro o adeus

A bebida não importa

Pode ser até suco de laranja

Salto alto, maquiagem, vestido de festa

Quando bate meia-noite a cama está pronta para um

mergulho

Não tiro a jóia

Pois quero sonhar com tubarões 
Em "Mergulho II" (p. 36) a persona lírica diáloga com um Narciso que mergulha "no reflexo do espelho" para "sair limpo" de si mesmo. Mesmo sendo cúmplice desse "Narciso sorridente, inocente", tenta dissuadi-lo do mergulho existencial, com o argumento da autocontemplação:

É melhor sucumbir

Ao namoro de teus olhos,

Narciso imprudente, inocente

O que pensas encontrar?

Vais em busca de um par?

A seguir, no entanto, o diálogo se completa com a cumplicidade inteiramente restabelecida:

É bom carregar pouco peso

Para quem sabe voltar

Para sair limpo

Para não ficar preso

Nas profundezas do espelho

No conto "O mergulho" (p. 85-87), o narrador em primeira pessoa é o protagonista Alberto, que realiza uma trajetória de aprendizado, simultaneamente, de liberdade e amor. Ele não sabe nadar e teme qualquer espelho d'água, mais ainda o mar. Como quase morrera afogado uma vez, sendo levado por uma onda, obedecia a seu pânico. Ana o convence graças a sua aceitação da dor existencial: "Eu já morri afogada em lágrima" (p. 86) e porque lhe promete revelar um segredo. Alberto, que se chamara a si mesmo de "pedra" (id.), conta na parte final:

Há um tesouro escondido no fundo do mar. Uma pedra raríssima que Ana sabe onde se encontra. Uma pérola preciosa, uma jóia moldada pela vida. Colhemos o presente e voltamos à superfície. A praia nos espera com seu sol menos doloroso. Estamos limpos e carregando uma pedra preciosa na mão. (p. 87) 
Vejo na poesia de Susana Vernieri e em seus ecos no conto um "Narciso imprudente" que, muito além da autocontemplação do Narciso mítico, ousa mergulhar nas imagens fragmentárias do espelho. Nesta comunicação, tomo os reflexos ao modo das "Instantâneas", cenas móveis, fluidas, pelas quais Beatriz Sarlo procura captar nossa contemporaneidade. A teórica argentina fala sobre seu método de examinar o detalhe: "são registros 'fotográficos' de experiências na cultura contemporânea, experiências diretas, voláteis, e, em alguns casos, esboçadas ante meu próprio olhar" (1996:7). Os poemas e a narrativa, como percepções - reflexos do espelho - do ato de mergulhar, são "Instantâneas" que oferecem ao leitor insights da experiência existencial, amorosa e de arte poética. Há uma busca de sair "limpo", e conseguir de fato o tesouro buscado, como na história do par Alberto-Ana, mas há também uma perspectiva tênue, indecisa, um "quem sabe" voltar. Sujeitos diferentes se dispõem, um, a mergulhar para o encontro com o obscuro de si mesmo, seus tubarões, num rito ambíguo, que se comemora por meio de "copo de cristal", mas com " até suco de laranja". Outro, a se atirar no rio e assim reatualizar, através e além do silêncio, a experiência da poesia.

Todos que lemos poetas atuais tendemos a ser cautelosos, como Alexei Bueno que fala, em seu livro Uma história da poesia brasileira, na montagem de um "guia sutil e móvel para o leitor" (2007:396). Ou Manoel da Costa Pinto, que explica ter feito sua Antologia comentada da poesia brasileira do século 21 mais na perspectiva do "leitor que vê na poesia um organismo vivo, em constante mutação, sujeito a avaliações no calor da hora, juízos provisórios e apostas" (2006:9). Pois que aí está em nossa cena literária a poesia de Susana Vernieri: com cuidado e atenção, escutemos seus segredos. 


\section{BIBLIOGRAFIA}

BUENO, Alexei. No agora e aqui pouco sabido. In: Uma história da poesia brasileira. Rio de Janeiro: G.Ermakoff, 2007. p. 396-407.

LYRA, Pedro. Sincretismo: a poesia da Geração 60: introdução e antologia. Rio de Janeiro: Topbooks, Fundação Rioarte; Fortaleza: Fundação Cultural de Fortaleza, 1995. MERQUIOR, José Guilherme. Verso universo em Drummond. Rio de Janeiro: J. Olympio, 1976.

PINTO, Manuel da Costa. Antologia comentada da poesia brasileira do século 21. São Paulo: Publifolha, 2006.

SARLO, Beatriz. Instantáneas: Medios, ciudad y costumbres en el fin de siglo. Buenos Aires: Espasa Calpe, 1996.

SECCHIN, Antonio Carlos. Poesia e desordem: escritos sobre poesia \& alguma prosa. Rio de Janeiro, Topbooks,1996.

VERNIERI, Susana. Memorabilia. Porto Alegre: Libretos, 2005. De(s)amores. Porto Alegre: Editora do Autor, 2007.

\section{NOTA}

1 O Resumo, incluindo as citações da poesia de Susana Vernieri, foi traduzido pela Profa. Ms. Rossana de Felippe Böhlke (FURG). 